\title{
Resección endoscópica de hamartoma gigante de glándulas de Brunner. Reporte de un caso
}

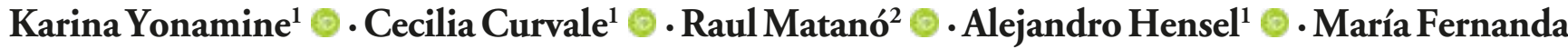 \\ Yankowyez 3 \\ ${ }^{1}$ Médica de planta Servicio de Gastroenterología. \\ 2 Jefe del Servicio de Gastroenterología. \\ ${ }^{3}$ Médico de planta Servicio de Anatomía Patológica. \\ Hospital de Alta Complejidad El Cruce. Florencio Varela, provincia de Buenos Aires, Argentina.
}

Acta Gastroenterol Latinoam 2021;51(3):341-346

Recibido: 03/04/2021 / Aceptado: 02/07/2021 / Publicado online: 27/09/2021 / https://doi.org/10.52787/gput6166

\section{Resumen}

El hamartoma o hiperplasia de glándulas de Brunner es una neoplasia benigna poco frecuente del intestino delgado, generalmente pequeña, cuyo hallazgo es incidental en una endoscopía digestiva alta o en estudios por imágenes. En el caso de que alcance un gran tamaño puede originar una hemorragia digestiva o una obstrucción intestinal. La patogénesis es desconocida. La presentación endoscópica puede ser nodular, polipoide o una proliferación glandular difusa con engrosamiento de la pared duodenal y confundirse con una neoplasia maligna. La resección endoscópica de los hamartomas de glándulas de Brunner de gran tamaño en duodeno se encuentra poco reportada en la bibliografía debido a su baja incidencia y su dificultad diagnóstica. El abordaje quirúrgico se asocia con mayor morbilidad en comparación con

Correspondencia: Karina Yonamine

Correo electrónico: yonaminekarina@gmail.com el abordaje endoscópico. Se reporta el caso de una paciente de 62 años, que debutó con melena y anemia sintomática, secundarias a un pólipo gigante en bulbo duodenal. El pólipo fue resecado exitosamente por vía endoscópica, sin complicaciones, lo que permitió evitar un procedimiento quirúrgico de mayor envergadura. El examen histopatológico de la pieza completa reveló un hamartoma de glándulas de Brunner. Conclusión: la hiperplasia o hamartoma de glándulas de Brunner es una neoplasia benigna que rara vez produce sintomas. Las lesiones grandes pueden tornarse sintomáticas y son necesarias una alta sospecha clinico-endoscópica y una evaluación de la extensión antes de aplicar cualquier procedimiento terapéutico, para asi evitar cirugias complejas y favorecer una resección endoscópica completa y segura.

Palabras claves. Glándulas de Brunner, pólipo duodenal, hamartoma, resección endoscópica.

\section{Endoscopic Resection of Gant Hamarto- ma of Brunner's Glands. A Case Report}

\section{Summary}

Brunner's gland hamartoma or hyperplasia is a rare benign neoplasm of the small intestine, usually small, that is discovered incidentally on an upper digestive endoscopy or imaging tests. When it reaches a large size, it can cause digestive bleeding or intestinal obstruction. The pathogenesis is unknown. The endoscopic presentation can be nodular, polypoid or a 
diffuse glandular proliferation with thickening of the duodenal wall, and may be mistaken for a malignant neoplasm. Endoscopic resections of large Brunner's gland hamartomas in the duodenum is little reported in literature, due to its low incidence and diagnostic difficulty. The surgical approach is associated to greater morbidity compared to an endoscopic approach. The case of a 62-year-old patient is reported, who presented melena and symptomatic anemia, secondary to a giant polyp in the duodenal bulb. The polyp was successfully resected endoscopically without complications, which made it possible to avoid a more extensive surgical procedure. Histopathological examination of the whole specimen showed a Brunner's gland hamartoma. Conclusion: Brunner's gland hyperplasia or hamartoma is a benign neoplasm that rarely produces symptoms. Large lesions can become symptomatic and a high clinical-endoscopic suspicion and an evaluation of the extension are necessary before applying any therapeutic procedure, in order to avoid complex surgeries and favor a complete and safe endoscopic resection.

Keywords. Brunner's gland; duodenal polyp; hamartoma; endoscopic resection.

\section{Abreviaturas}

EDG: Endoscopia digestiva alta.

TC: Tomografía axial computada.

RM: Resonancia nuclear magnética.

EUS: Ecoendoscopía.

TNE: Tumor neuroendócrino.

GIST: Tumor del estroma gastrointestinal.

EMR: Resección mucosa endoscópica.

ESD: Disección submucosa endoscópica.

\section{Introducción}

Los pólipos o lesiones duodenales son hallazgos poco frecuentes en la endoscopía digestiva alta (EDG) y corresponden a menos del $1 \%$ de todos los tumores gastrointestinales. ${ }^{1}$ Pueden clasificarse, según la capa de la pared que les da origen, en subepiteliales o mucosos, y el tipo de lesión orienta la posible opción terapéutica. Los métodos por imágenes como la tomografía computada (TC), la resonancia magnética (RM) o la ecoendoscopía (EUS) son útiles en el diagnóstico y la caracterización, principalmente de las lesiones subepiteliales. ${ }^{2}$

Las glándulas de Brunner son glándulas de secreción alcalina localizadas en la mucosa y la submucosa, de mayor concentración en el bulbo duodenal, aunque también pueden encontrarse en el píloro, en el resto del duodeno y en el yeyuno. Su rol en la digestión es controversial. ${ }^{3}$
La hiperplasia y el hamartoma de glándulas de Brunner son lesiones polipoides o masas poco frecuentes, de naturaleza benigna y con una incidencia estimada de menos del 0,01\%. Generalmente es un hallazgo incidental de un pólipo pediculado único en una EDG, con un promedio de tamaño de $2 \mathrm{~cm}$. La nomenclatura en relación con las lesiones de las glándulas de Brunner es confusa. No existen casos reportados de displasia (adenoma) o carcinoma que se asienten sobre una proliferación de glándulas de Brunner. Aunque algunos reportes describen casos raros de adenocarcinoma, la mayoría no muestra de manera inequívoca una neoplasia de novo dentro de estas glándulas, sino más bien el compromiso secundario por displasia o carcinoma que surge desde la superficie mucosa. Por lo tanto, se prefiere el uso del término hiperplasia de glándulas de Brunner (más que adenoma) para describir la mayoría de las lesiones proliferativas de estas glándulas, debido a que esta terminología refleja mejor la naturaleza no neoplásica de esta entidad. ${ }^{4,5}$

El acuerdo entre patólogos para la distinción entre hiperplasia de glándulas de Brunner y hamartoma es arbitrario. Si la lesión es menor de 5-10 mm de tamaño, ya sea solitaria o múltiple, se denomina hiperplasia. Si la lesión es mayor de $10 \mathrm{~mm}$, habitualmente pediculada, se denomina hamartoma. El tamaño es el parámetro más útil para el manejo clínico, debido a que las lesiones grandes y solitarias son las que generalmente producen síntomas. ${ }^{2,4,6}$

Los pólipos resultantes de la hiperplasia de glándulas de Brunner son típicamente pequeños y se caracterizan por ser lobulaciones de las glándulas, las cuales se hallan incrementadas en tamaño y número. Los pólipos pediculados mayores a $2 \mathrm{~cm}$ compuestos por glándulas de Brunner, causantes de síntomas de obstrucción, intususcepción, melena o anemia, son detectados ocasionalmente. Algunos investigadores han elegido el término de hamartoma de glándulas de Brunner para enfatizar sus características inusuales, que incluyen abundante tejido fibromuscular, tejido adiposo, glándulas quísticas dilatadas y una proliferación florida de las glándulas de Brunner. El diagnóstico es sencillo en piezas de resección completa, aunque dificultoso en las biopsias endoscópicas de la superficie mucosa. ${ }^{5}$

Estas lesiones benignas son pasibles de resección endoscópica en aquellos casos sintomáticos y cuya localización y tamaño permitan adecuadamente la técnica resectiva por esta vía. Su diagnóstico diferencial, muchas veces complejo, en especial con lesiones malignas, requiere una evaluación exhaustiva por métodos de imágenes que permitan determinar su extensión y la planificación multidisciplinaria de su resección. 


\section{Caso clínico}

Se presenta el caso de una mujer de 62 años, con antecedentes de aneurisma cerebral operado hace varios años, hipertensión arterial y diabetes con requerimientos de insulina. Consultó en varias oportunidades, meses previos a la internación, por saciedad precoz, distensión y dolor abdominal ocasional. En una oportunidad se le realizó EDG, en la que se evidenció una lesión polipoide en bulbo duodenal de 50 x $20 \mathrm{~mm}$, cuya biopsia informó pólipo hiperplásico con cambios adenomatosos focales (displasia de bajo grado). La paciente no continuó con las visitas médicas y seis meses más tarde agregó episodios de melena y anemia sintomática, por lo que se derivó su consulta al servicio de emergencias. Ingresó con una hemoglobina de $7 \mathrm{~g} / \mathrm{dL}$. Se le realizó en la sala de emergencias una endoscopía que evidenció la lesión polipoide en el bulbo duodenal, previamente descrita, de aproximadamente $50 \times 20 \mathrm{~mm}$, congestiva y móvil, con restos hemáticos escasos. La paciente fue derivada al servicio de cirugía de nuestra insti- tución para la resolución quirúrgica del cuadro. Al ingreso se constató melena franca en el tacto rectal y una hemoglobina de $9 \mathrm{gr} / \mathrm{dL}$ postransfusión de sedimento globular. Se solicitó una TC de abdomen con doble contraste, en la que se observó una lesión polipoide en bulbo duodenal, con extensión a la segunda porción y crecimiento intraluminal de 50 × $20 \mathrm{~mm}$, con realce heterogéneo tras la administración de contraste endovenoso, alcanzando el equilibrio en fase tardía (Figura 1). No se encontró evidencia de extensión hacia la profundidad de la pared duodenal ni presencia de adenomegalias patológicas.

Se analizaron los diagnósticos diferenciales (Tabla 1) ${ }^{2}$ y se decidió realizar un intento endoscópico de resección, ya que se encontraba en una posición accesible y sin evidencia endoscópica ni imagenológica de compromiso del espesor parietal duodenal. La base de implantación ancha del pólipo se encontró en bulbo, de aproximadamente $25 \mathrm{~mm}$, hacia la pared superior y anterior, con su extremo móvil en segunda porción duodenal (Figura 2).

Figura 1. Tomografía computada: los hamartomas de glándulas de Brunner son predominantemente isodensos en relación con el páncreas en TAC sin contraste, e hipodensos luego de la administración de contraste iodado.
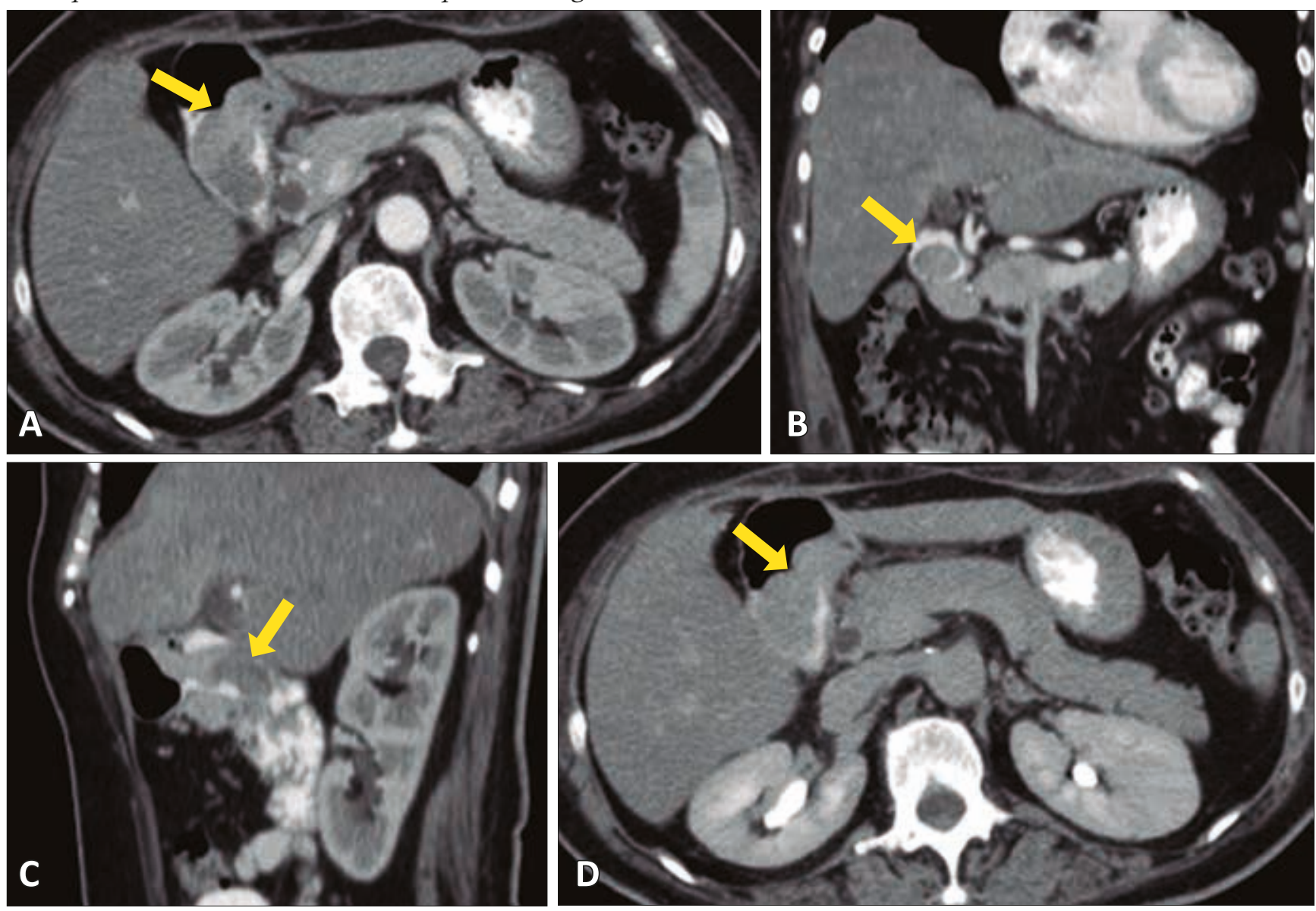

Puede visibilizarse un anillo periférico de realce durante la fase arterial y luego homogeneizarse durante la fase tardía. A) Corte axial, fase arterial. B) Corte coronal. C) Corte sagital. D) corte axial, fase tardía. 
Tabla 1. Diagnósticos diferenciales de pólipo duodenal ${ }^{2}$

\begin{tabular}{|c|c|c|c|c|}
\hline $\begin{array}{l}\text { Tipo de lesión } \\
\text { duodenal }\end{array}$ & $\begin{array}{l}\text { Capa de la pared } \\
\text { duodenal (según EUS) }\end{array}$ & $\begin{array}{l}\text { Potencial } \\
\text { maligno }\end{array}$ & $\begin{array}{l}\text { Requiere } \\
\text { resección }\end{array}$ & $\begin{array}{l}\text { Pasible de resección } \\
\text { endoscópica }\end{array}$ \\
\hline Lipoma & Tercera capa (submucosa) & NO & NO & sí \\
\hline GIST & Cuarta capa (muscular propia) & sí & sí & $\begin{array}{l}\text { Sí, en lesiones pequeñas. } \\
\text { La mayoría es quirúrgica }\end{array}$ \\
\hline TNE & Tercera capa (submucosa) & Sí & Sí & $\begin{array}{l}\text { Es posible si es una lesión } \\
\text { solitaria y pequeña }\end{array}$ \\
\hline $\begin{array}{l}\text { Hamartoma de } \\
\text { glándulas de Brunner }\end{array}$ & $\begin{array}{l}\text { Primera a tercera capa } \\
\text { (mucosa y submucosa) }\end{array}$ & NO & $\begin{array}{l}\text { Si se vuelven } \\
\text { sintomáticos }\end{array}$ & Sí \\
\hline $\begin{array}{l}\text { Hamartoma solitario de } \\
\text { Peutz-Jeghers }\end{array}$ & Primera capa (mucosa) & sí & sí & Sí \\
\hline Adenoma & Primera capa (mucosa) & sí & sí & sí \\
\hline
\end{tabular}

GIST: tumor del estroma gastrointestinal; TNE: tumor neuroendocrino.

Con el objetivo de prevenir la complicación principal, que es la hemorragia pospolipectomía, se realizó profilaxis doble mediante la inyección de adrenalina 1:10.000 en la base del pólipo, e inmediatamente posterior a la resección completa con asa diatérmica en única pieza, se colocó un clip hemostático aproximando los márgenes. Debido al gran tamaño de la lesión, se dificultó su extracción a través del píloro, logrando su exteriorización completa mediante la utilización de una canastilla rígida extractora de cálculos.

Figura 2. Imágenes endoscópicas y pieza resecada
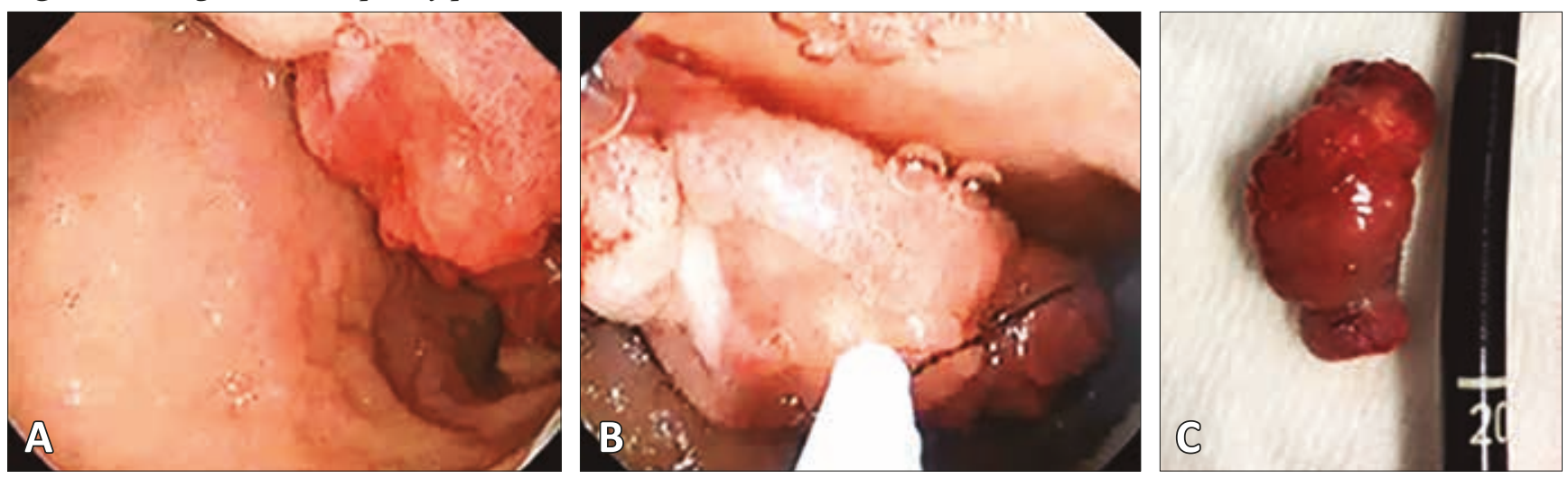

A) Pólipo con base de implantación en bulbo duodenal. B) Extensión del pólipo hacia segunda porción duodenal. Enlazado con asa multifilamento de 25 mm. C) Pólipo resecado de $55 \times 25$ mm de diámetro máximo.

No se presentaron complicaciones durante el procedimiento ni posteriormente. La paciente fue dada de alta a las 24 horas.

\section{Seguimiento y resultados}

La paciente recuperó la hemoglobina y no repitió los episodios de sangrado luego de cuatro meses de seguimiento. Continuó totalmente asintomática. El control endoscópico demostró la presencia de una cicatriz en el sitio de resección, sin recidiva (Figura 3 ).

El informe de la anatomía patológica describió en la macroscopía una formación polipoide, de color pardo

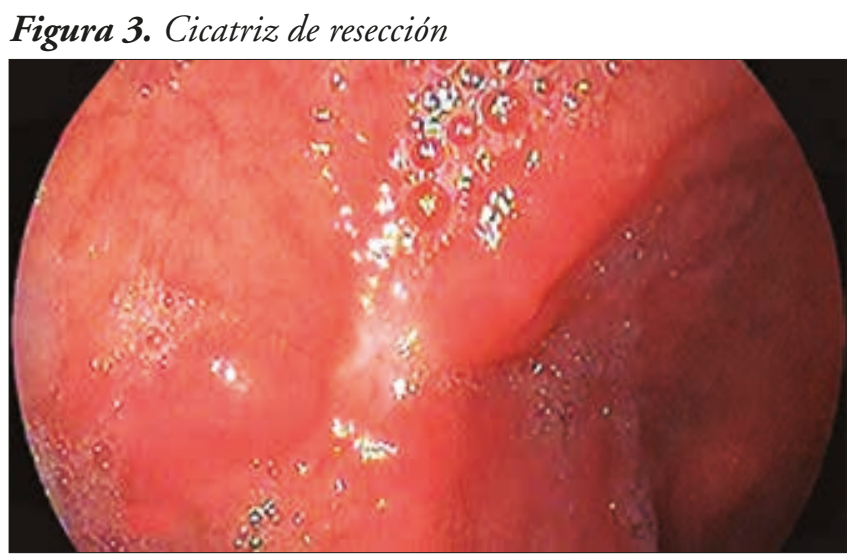


claro, de 55 x 25 x $25 \mathrm{~mm}$. Al corte resultó blanquecino heterogéneo, de consistencia duro-elástica.

En la microscopía se observó una proliferación benigna compacta de células de Brunner, dispuestas en lóbulos, separados por tejido fibroconectivo y delicados haces de músculo liso. Por sectores se observaron tabiques de colágeno y un estroma mixoide laxo (Figura 4). Los hallazgos histológicos fueron vinculables a hamartoma de glándulas de Brunner.

\section{Discusión}

El duodeno, a diferencia de otros sitios del tracto digestivo, es asiento de un grupo diverso y heterogéneo de desórdenes con diferente riesgo de transformación maligna o de presentación sintomática. La mayoría de las estructuras polipoides duodenales provienen de la capa mucosa, dando lugar a los adenomas premalignos, aunque, en ciertas ocasiones, determinadas patologías subepiteliales pueden causar protrusión de tejido dentro de

Figura 4. Proliferación benigna compacta de células de Brunner dispuestas en lóbulos, separados por tejido fibroconectivo y delicados haces de músculo liso. Tabiques de colágeno y estroma mixoide laxo, con ocasionales histiocitos, distorsión y dilatación glandular, quistificación focal y células epiteliales de revestimiento de aspecto reactivo. Microfocos de hemorragia, congestión vascular y algunos vasos trombosados y recanalizados. Epitelio de revestimiento intestinal con áreas de exulceración y cambios reactivos y regenerativos.
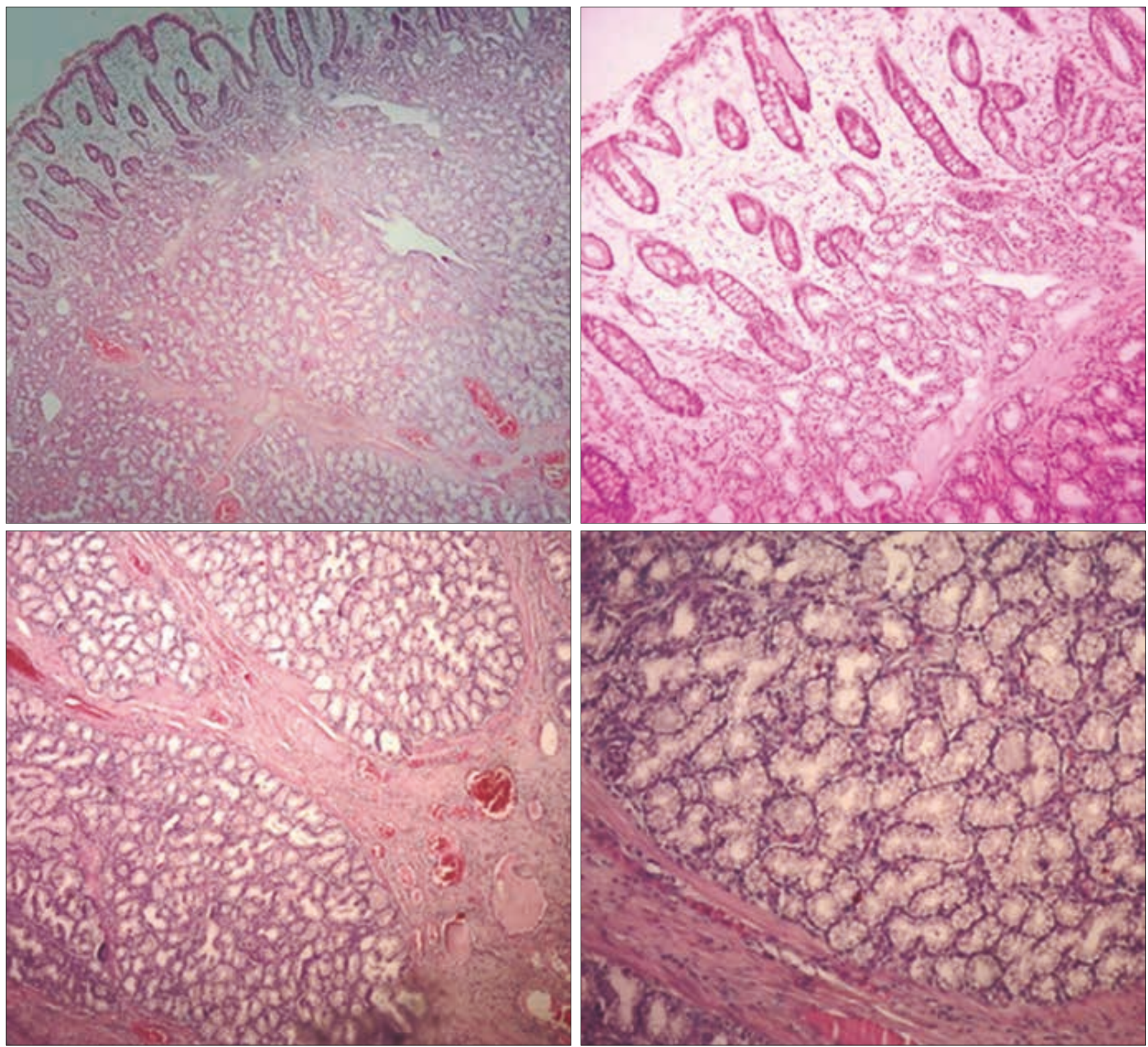
la luz intestinal, simulando pólipos mucosos. Dentro de este subgrupo se incluyen las masas subepiteliales benignas como el hamartoma de glándulas de Brunner o los lipomas. Otras lesiones subepiteliales menos frecuentes con riesgo de malignización incluyen los TNE (carcinoides, gastrinomas, paragangliomas) y los GISTs. ${ }^{7}$

Los hamartomas de glándulas de Brunner son ramificaciones acinotubulares de localización submucosa que se encuentran preferentemente entre el anillo pilórico y la ampolla de Vater. Son lesiones benignas, poco frecuentes, generalmente incidentales, pero que pueden presentarse asociadas a síntomas según su tamaño. ${ }^{1}$

Las células que constituyen las glándulas son pequeñas y contienen abundante mucina neutral y un núcleo localizado basalmente con mínima o ausencia de actividad mitótica. ${ }^{5}$ El diagnóstico final de esta patología se realiza mediante la evaluación de la pieza completa, ya que se origina esencialmente en la tercera capa (submucosa), la cual no puede evidenciarse en las biopsias endoscópicas habituales.

Dado el riesgo de confusión potencial con lesiones neoplásicas en imágenes radiológicas o en el examen endoscópico, es importante considerar estas entidades dentro de los diagnósticos diferenciales, ya que implican diferentes estrategias terapéuticas. El riesgo de complicaciones mayores en la resección endoscópica duodenal se encuentra incrementado, principalmente para la hemorragia pospolipectomía o la perforación, en comparación con la resección de lesiones en otras localizaciones del tubo digestivo. Por otro lado, la opción quirúrgica se asocia con un riesgo no desestimable de mortalidad perioperatoria y morbilidad digestiva a largo plazo, debido a la disrupción de la anatomía y la fisiología normales, incluso en centros de gran volumen. ${ }^{7}$

Hoy en día, la remoción endoscópica de las lesiones duodenales es electiva y se ha instalado como una modalidad terapéutica segura si se utiliza un adecuado equipamiento endoscópico en operadores con experiencia. Las técnicas de resección de lesiones polipoides mediante utilización de asa, previa inyección o utilización de Endoloop como método preventivo de hemorragia pospolipectomía, o las técnicas de EMR (resección mucosa endoscópica) o ESD (disección submucosa endoscópica) para las lesiones planas, han sido introducidas como métodos de resección seguros para las lesiones benignas. Sin embargo, tanto la EMR como la ESD son procedimientos que requieren un endoscopista experto, no solo por la dificultad técnica en sí misma, sino también por la anatomía de la región. ${ }^{1,2}$

En conclusión, las técnicas de resección pueden ser endoscópicas, quirúrgicas o combinadas, y la decisión acerca de cuál usar depende de múltiples factores.

Este caso resultó interesante ya que un procedimien- to mínimamente invasivo como es la endoscopía, previa planificación de su extirpación, permitió la resección de la lesión y evitó la realización de un procedimiento quirúrgico de mayor envergadura y morbilidad.

La alta sospecha clínica, la planificación terapéutica (endoscópica/quirúrgica) y un patólogo avezado son fundamentales para el diagnóstico y la buena evolución de estas patologías poco frecuentes.

Consentimiento para la publicación. Para la confección de este manuscrito, se utilizaron datos anonimizados que no han distorsionado su significado cientifico.

Propiedad intelectual. Los autores declaran que los datos, las figuras y las tablas presentes en el manuscrito son originales y fueron realizados en sus instituciones pertenecientes.

\section{Aviso de derechos de autor}

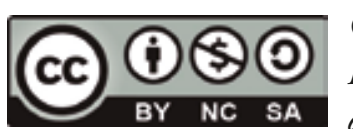

(C) 2021 Acta Gastroenterológica Latinoamericana. Este es un artículo de acceso abierto publicado bajo los términos de la Licencia Creative Commons Attribution (CC BY-NC-SA 4.0), la cual permite el uso, la distribución y la reproducción de forma no comercial, siempre que se cite al autor y la fuente original.

Cite este artículo como: Yonamine $K$, Curvale $C$, Matanó $R$ y col. Resección endoscópica de hamartoma gigante de glándulas de Brunner: reporte de un caso. Acta Gastroenterol Latinoam. 2021;51(3):341-6. https://doi. org/10.52787/gput6166

\section{Referencias}

1. Sorleto M, Timmer-Stranghöner A, Wuttig H, Engelhard O, Gartung C. Brunner's Gland Adenoma - A Rare Cause of Gastrointestinal Bleeding: Case Report and Systematic Review. Case Rep Gastroenterol. 2017;11(1):1-8.

2. Gaspar JP, Stelow EB, Wang AY. Approach to the endoscopic resection of duodenal lesions. World J Gastroenterol. 2016;22(2):600-17.

3. Hur S, Han JK, Kim MA, Bae JM, Choi BI. Brunner's gland hamartoma: Computed tomographic findings with histopathologic correlation in 9 cases. J Comput Assist Tomogr. 2010;34(4):543-7.

4. Patel ND, Levy AD, Mehrotra AK, Sobin LH. Brunner's gland hyperplasia and hamartoma: Imaging features with clinicopathologic correlation. Am J Roentgenol. 2006;187(3):715-22.

5. Odze RD, Goldblum JR. Odze and Goldblum surgical pathology of the GI tract, liver, biliary tract, and pancreas. In: Elsevier Health Sciences. 2014:722-36.

6. Barat M, Dohan A, Dautry R, Barral M, Boudiaf M, Hoeffel C, et al. Mass-forming lesions of the duodenum: A pictorial review. Diagn Interv Imaging. 2017;98(10):663-75.

7. Bourke MJ. Endoscopic resection in the duodenum: Current limitations and future directions. Endoscopy. 2013;45(2):127-32. 